\title{
Microarray expression profiles of genes in lung tissues of rats subjected to focal cerebral ischemia-induced lung injury following bone marrow-derived mesenchymal stem cell transplantation
}

\author{
YUE HU $^{1}$, LIU-LIN XIONG ${ }^{1}$, PIAO ZHANG ${ }^{2}$ and TING-HUA WANG ${ }^{1,2}$ \\ ${ }^{1}$ Department of Anesthesiology, Institute of Neurological Disease, Translational Neuroscience Center, \\ West China Hospital, Sichuan University, Chengdu, Sichuan 610041; ${ }^{2}$ Institute of Neuroscience, \\ Kunming Medical University, Kunming, Yunnan 650031, P.R. China
}

Received December 22, 2015; Accepted November 21, 2016

DOI: $10.3892 / \mathrm{ijmm} .2016 .2819$

\begin{abstract}
Ischemia-induced stroke is the most common disease of the nervous system and is associated with a high mortality rate worldwide. Cerebral ischemia may lead to remote organ dysfunction, particular in the lungs, resulting in lung injury. Nowadays, bone marrow-derived mesenchymal stem cells (BMSCs) are widely studied in clinical trials as they may provide an effective solution to the treatment of neurological and cardiac diseases; however, the underlying molecular mechanisms remain unknown. In this study, a model of permanent focal cerebral ischemia-induced lung injury was successfully established and confirmed by neurological evaluation and lung injury scores. We demonstrated that the transplantation of BMSCs (passage 3) via the tail vein into the lung tissues attenuated lung injury. In order to elucidate the underlying molecular mechanisms, we analyzed the gene expression profiles in lung tissues from the rats with focal cerebral ischemia and transplanted with BMSCs using a Gene microarray. Moreover, the Gene Ontology database was employed to determine gene function. We found that the phosphoinositide 3-kinase (PI3K)-AKT signaling pathway, transforming growth factor- $\beta$ (TGF- $\beta$ ) and platelet-derived growth factor (PDGF) were downregulated in the BMSC transplantation groups, compared with the control group. These results suggested that BMSC transplantation may attenuate lung injury following focal cerebral ischemia and that this effect is associated with the downregulation of TGF- $\beta$, PDGF and the PI3K-AKT pathway.
\end{abstract}

Correspondence to: Professor Ting-Hua Wang, Department of Anesthesiology, Institute of Neurological Disease, Translational Neuroscience Center, West China Hospital, Sichuan University, Section 3, 17 South Renmin Road, Chengdu, Sichuan 610041, P.R. China E-mail: tinghua_neuron@263.net

Key words: lung injury, permanent focal cerebral ischemia, bone marrow-derived mesenchymal stem cell transplantation, microarray analysis

\section{Introduction}

Ischemic stroke is recognized as one of the catastrophic threats to the human health, and is associated with an increasing morbidity worldwide. An estimated 700,000 cases of ischemic stroke occur in the United States each year, costing $>\$ 70$ billion to society (1). Cerebral ischemia can cause severe damage, such as neuronal apoptosis or death, glial cell activation and proliferation, inflammatory reaction and stress response $(2,3)$. Cerebral ischemia can also cause many remote organ dysfunctions (4-12); a previous study indicated that brain ischemia can cause lung injury (13).

Mesenchymal stem cells (MSCs) are a type of stem cell derived from the mesoderm, and primarily exist in the connective tissue of the body and organ interstitial space, particularly the bone marrow. Bone marrow-derived mesenchymal stem cells (BMSCs), are one of the main types of stem cells and have the ability of self-proliferation (14), self-renewal and the potential to differentiate into other cells in peripheral tissue (15). Recently, studies using BMSCs have achieved positive results in the treatment of degenerative and defective diseases, cardiovascular disease, liver transplantation, pulmonary fibrosis and other diseases (14-17). Previous studies have reported that transplanted BMSCs can home to damaged lung tissues and differentiate into lung epithelial cells, as well as vascular endothelial cells, and can then regulate the inflammatory response in acute lung injury (ALI); thus, they are involved in repairing injured lungs $(18,19)$. Furthermore, studies have demonstrated that BMSC transplantation has therapeutic effects of ALI/acute respiratory distress syndrome (ARDS) by releasing soluble factors, reducing pulmonary capillary endothelium permeability and alveolar edema, alleviating lung inflammation, promoting cell proliferation and inhibiting cell apoptosis $(20,21)$. Although a large number of studies have demonstrated that stem cell transplantation has some protective effects on the lungs, the cell biology and molecular biological mechanisms of action of BMSCs in vivo are not yet entirely understood, and in particular, the mechanisms of BMSCs in lung injury caused by cerebral ischemia.

Gene microarray (22), as a high throughput technology for life sciences and microelectronics, has been widely investigated and is widely used in various research areas of biology 
and medicine in bioinformatics research in recent years. It provides important theoretical and practical values in sequence analysis, gene expression, genome research and the intensity of hybridization signals of gene expression profiles. It is able to yield large-scale, high-throughput information, integrating a range of biological information (23). Thus, in the present study, in order to elucidate the potential molecular mechanisms responsible for the protective role of BMSC transplantation into the lungs, gene microarray analysis was used.

The present study was therefore undertaken to investigate the protective effects of BMSC transplantation on rat lung injury following permanent focal cerebral ischemia, and to explore the related molecular mechanisms using Gene microarray and Gene Ontology (http://www.geneontology.org/).

\section{Materials and methods}

Experimental animals and grouping. A total of 27 healthy adult female SD rats, 2 months old, weighing $220 \pm 10 \mathrm{~g}$ were provided by the Experimental Animal Center of Kunming Medical University, Kunming, China. Animal care and all experimental protocols were approved by the Animal Care Committee of Sichuan University, West China Hospital, Chengdu, China and according to the guidelines of the Unites States National Institutes of Health. All animals were raised in plastic cages ( $\mathrm{n}=2 /$ cage) with soft bedding and free access to food and water in a temperature $\left(21-25^{\circ} \mathrm{C}\right)$ and humidity (45-50\%)-controlled room. The rats were randomly divided into the sham-operated group (Sham), the brain ischemia (BI) group and the BMSC transplantation [BMSCs (t)] group ( $\mathrm{n}=8$ rats in each group). The animals in the $\mathrm{BI}$ group were subjected to permanent focal brain ischemia and treated with culture medium. The animals in the BMSCs (t) group were subjected to BI and injected with the BMSC suspension at 9 days following injury. The animals in the sham-operated group were not subjected to either BI or to transplant injections.

Animal model of permanent focal cerebral ischemia. A model of permanent focal cerebral ischemia was established by occlusion of the middle cerebral artery (MCAO) as previously described (24). Briefly, the SD rats were anesthetized deeply by an intraperitoneal injection of $2 \%$ pentobarbital sodium $(30 \mathrm{mg} /$ $\mathrm{kg}$ ) and immobilized in the supine position for skin preparation. After the left external carotid artery section was exposed, a small hole was created in the free section and a thread (purchased from Beijing Cinontech Co., Ltd., Beijing, China) was inserted from the bifurcation of the common carotid artery into the internal carotid artery, and then into the beginning of the middle cerebral artery. Thread insertion was approximately $18.5 \pm 0.5 \mathrm{~mm}$ deep. The sham-operated group insertion was approximately $1 \mathrm{~cm}$.

BMSC culture and purification. BMSCs were harvested from the femurs and tibias of $3 \mathrm{SD}$ rats. Briefly, after the rats were euthanized with a mixture of $70 \% \mathrm{CO}_{2}$ and $30 \% \mathrm{O}_{2}$, the femurs and tibias were dissected in a sterile environment and rinsed with D-Hanks solution. The epiphyses of the femurs and tibias were removed, and the marrow was then extruded using a syringe filled with DMEM/F12 containing 10\% fetal bovine serum (FBS; Gibco, Gaithersburg, MD, USA), and repeatedly beated into a single cell suspension with $5 \mathrm{ml}$ DMEM/F12 containing
10\% FBS and penicillin/streptomycin. Following centrifugation ( $800 \mathrm{x} \mathrm{g}$ for $5 \mathrm{~min}$ ) and re-suspension, $5 \mathrm{ml}$ of cell suspension was collected, and the cells were plated in $25 \mathrm{~cm}^{2}$ culture flasks at a density of $3 \times 10^{5} \mathrm{cells} / \mathrm{ml}$ in an incubator $\left(37^{\circ} \mathrm{C}, 95 \%\right.$ humidity, $5 \% \mathrm{CO}_{2}$ ). After $24 \mathrm{~h}$, the supernatant containing non-adherent cells was removed and fresh medium was added. The medium was changed every 3-5 days, after the cells had grown to near confluence and the density was approximately (4-5)x $10^{5}$ cells/ $\mathrm{cm}^{2}$; the cells were passaged 3 times and the suspended cells were discarded. Subsequently, the pure adherent cells (BMSCs) were cultivated for further analysis. The growth status of the cultured BMSCs was observed under an inverted phase contrast microscope (Leica Microsystems GmbH, Wetzlar, Germany).

Immunohistochemistry. In previous studies, it was found that the growth status of BMSCs in passage 3 was better than that in passage 1 or $2(25,26)$. Therefore, BMSCs at passage 3 were used in this study. To identify the cultured BMSCs, the purified BMSCs, derived from passage 3 before transplantation, were fixed with $4 \%$ paraformaldehyde for $10 \mathrm{~min}$, and phosphate buffered-saline (PBS) $(0.01 \mathrm{~mol} / \mathrm{l})$ was used to wash the cells 3 times (5 min/time). The specific methods for identification are listed below, according to immunohistochemical twostep staining: washing with $0.01 \mathrm{~mol} / \mathrm{l}$ PBS 3 times $(5 \mathrm{~min} /$ time), incubating with $0.3 \%$ Triton X-100 for $30 \mathrm{~min}$ at $37^{\circ} \mathrm{C}$, incubation with $5 \%$ goat serum for $30 \mathrm{~min}$ at $37^{\circ} \mathrm{C}$ to block non-specific binding sites; incubation with primary antibody to CD44 (1:100; ZA-0537; Beijing Zhongshan Golden Bridge Biotechnology Co., Ltd., Beijing, China) at $4^{\circ} \mathrm{C}$ for $24 \mathrm{~h}$ (the negative control was only incubated with $2 \%$ sheep serum); washing with $0.01 \mathrm{~mol} / 1 \mathrm{PBS} 3$ times (5 min/time); and incubation with Alexa Fluor-labeled 594 goat anti-rabbit IgG (secondary antibody, 1:100; ZF-0516; Beijing Zhongshan Golden Bridge Biotechnology Co., Ltd.) for $60 \mathrm{~min}$ at $37^{\circ} \mathrm{C}$. The cells were then observed and iamged using a fluorescent microscope (Leica Microsystems GmbH).

Cell transplantation. Cyclosporine A (10 mg/ $\mathrm{kg}$ body weight) was intraperitoneally injected 3 days prior to cell transplantation; Hoechst 33342 (Beyotime Institute of Biotechnology, Jiangsu, China) was used to stain the prepared cells prior to transplantation in order to be able to trace the cells after transplantation. Approximately $6 \mu \mathrm{l}$ BMSCs $\left(1 \times 10^{6} / \mathrm{ml}\right)$ at passage 3 were slowly transplanted to the tail vein at the 9th day post-surgery. Cyclosporine A (10 mg/kg body weight) and penicillin (20 U/ one) were injected at $24 \mathrm{~h}$ post-cell transplantation until day 3 . Cyclosporine A was used before and after transplantation.

Behavioral evaluation. In order confirm that the animal model was successfully created and to detect behavioral changes post-surgery, neurological deficit evaluation was performed before and $4 \mathrm{~h}$ post-surgery, in accordance with the scoring method described in the study by Menzies et al (27): 0 points, no neurological damage, double forelimb symmetric stretching to the ground; 1 point, contralateral forelimb sustained adduction; 2 points, contralateral forelimb grip strength decreased; 3 points, a slight stimulation of rat tails to the contralateral circling; 4 points, independent continuous circular motion. The animals in the model group with a score $\geq 1$ were selected for analysis in further experiments and were randomly 
equivalently divided into the BMSCs (t) group and the culture medium injection (BI) group.

In order to better assess the effects of BMSC transplantation on neurological function, a more detailed scoring criteria that was double-blind was evaluated at 4:00 p.m. at 0, 3, 7 and 14 days post-transplantation. The improved neurological evaluation score ranged between $0-18$ points as follows: 0 points, no neurological damage; $1-6$ points, mild injury; 7-12 points, moderate injury; 13-18 points, severe damage.

Tissue harvest. At 14 days post-transplantation, the experimental and sham animals were sacrificed by cutting the abdominal aorta following an intraperitoneal injection of $2 \%$ pentobarbital sodium. The lung tissues were removed immediately after cutting the abdominal aorta for further histological and molecular analyses. The specific steps were as follows:

Hematoxylin and eosin $(H \& E)$ staining. At 14 days post-transplantation, all the rats were sacrificed as described above, and the harvested lung tissues were fixed with $4 \%$ paraformaldehyde in $0.1 \mathrm{M}$ ice-cold phosphate buffer, $\mathrm{pH} 7.4$, for at least $72 \mathrm{~h}$ at $4^{\circ} \mathrm{C}$. The fixed lung tissues were then embedded in paraffin and sectioned at a thickness of $5 \mu \mathrm{m}$, transferred to glass slides, and stained with H\&E (C0105; Beyotime Institute of Biotechnology). Subsequently, the lung morphological changes in each group were observed under a light microscope (RX50 series biological microscope; Sunny Optical Technology (Group), Co., Ltd.).

Lung injury pathological score. In order to evaluate the lung injury following BI, the pathological score was assessed by 3 researchers blinded to the experiment. The extent of the pathological injury was determined using the following 4 categories: alveolar septa, alveolar hemorrhage and intra-alveolar fibrin, intra-alveolar infiltrations per field. The final average total lung injury scores of the 4 categories were the mean values from the 3 researchers, as previously described (28).

Total RNA extraction and microarray analysis. Microarray analysis was performed by Shanghai Kangcheng Biological Co (Shanghai, China). for a 'whole genome expression profiling gene chip of rat' test. Briefly, total RNA was extracted using TRIzol agent and DNA concentration and purity were measured using a UV spectrophotometer and qualified by agarose gel electrophoresis. The One-cycle cDNA synthesis kit (obtained from Affymetrix, Santa Clara, CA, USA, $\mathrm{P} / \mathrm{N}$ 900431; following the operating instructions) was used to perform reverse transcription to obtain cDNA, which was then purified. After using the Gene Chip IVT labeling kit to synthesize biotin-labeled cDNA in vitro, the cDNA were hybridized with Gene Chip following fragmentation. This was followed by washing and staining, and finally the fluorescence signal intensity of gene expression with a scanner was obtained, and then corrected using the reference gene. Signal processes were detected using the Gene Ontology database (http://www.geneontology.ogy.org/); the analysis includes biological process (BP) that are composed by orderly composition of molecular function and a process of multiple steps; cell components (CC), namely the position of the cell in which the gene product is located in the cell or gene products group (e.g., the rough endoplasmic reticulum, nucleus or ribosomes and proteasomes); and molec- ular function (MF) that describes the activity in molecular biology. Each section has 4 small parts: 1, the analysis of gene number (count), namely the number of differentially expressed genes measured in this function group; 2, P-value trees, namely thecascade relationship of biological pathway; 3 , enrichment factor (fold enrichment), that is, the proportion of the changes in genes than proportions in the GO database in this function group (such as, the more proportion, the more reliability, which was regarded as the more significant changes in molecular function); 4, enrichment points, with enrichment factor empathy. Pathway analysis was performed using the KEGG database (http:// www.genome.jp/kegg/pathway.html) or DAVID Bioinformatics Resources (https://david.ncifcrf.gov/).

Data analysis. The Agilent Feature Extraction software (version 10.7.3.1) was used to analyze the acquired array images as previously described (29).

Staistical analysis. In this study, SPSS software (version 17.0; SPSS Inc., Chicago, IL, USA) was used to process the data, and the experimental results are expressed as the means \pm standard deviation (SD); one-way analysis of variance (ANOVA) was used to compare the differences between the sham-operated group and the experimental groups; a value of $\mathrm{P}<0.05$ was considered to indicate statistically significant differences. For statistical analysis and gene scanning, we used Microarray Suite version 5.0 software to analyze the strength and the ratio of hybridization signals, and the chip data with the normalization process; SMA software was used for the statistical analysis of the results, according to the conventional standard q-value (\%) 5\% screening of the differentially expressed genes.

\section{Results}

BMSC cell culture, purification and identification. The BMSCs appeared to be in good condition, and some adherent round cells could be observed at $24 \mathrm{~h}$ of culture (Fig. 1A); at 48-72 $\mathrm{h}$ of culture, the cultured cells slowly grew into spindle- and polygonal-shaped cells with an orbicular-ovate nucleus (Fig. 1B). The amount of BMSCs increased at 5 days of culture, and the cells gradually developed into a spindle shape and were distributed radially (Fig. 1C). To identify the cultured cells, immunofluorescence staining of CD44 at passage 3 was performed and the results revealed that the $99.3 \%$ of the cells were CD44-positive (Fig. 1E). These results confirmed that the cultured cells were BMSCs at passage 3 (Fig. 1D).

Role of BMSC transplantation. The lung tissues harvested at 14 days post-transplantation emitted a large blue Hoechst 33342 florescence, demonstrating the survival and migration of the transplanted BMSCs in lung tissues (Fig. 2A). However, we did not find NeuN- and GFAP-positive cells in the lung tissues (data not shown). Neurological evaluation based on a 0-18 point scording system revealed that all the animals before surgery had a score of $0.0000 \pm 0.00000$ points, and there were no statistically significant differences among the rats $(\mathrm{P}>0.05)$. Following surgery, at 3, 7 and 14 days post-transplantation, as compared with the sham-operated group, the scores in the BI group were significantly higher $(\mathrm{P}<0.05)$, while BMSC transplantation significantly attenuated the neurological injury, 

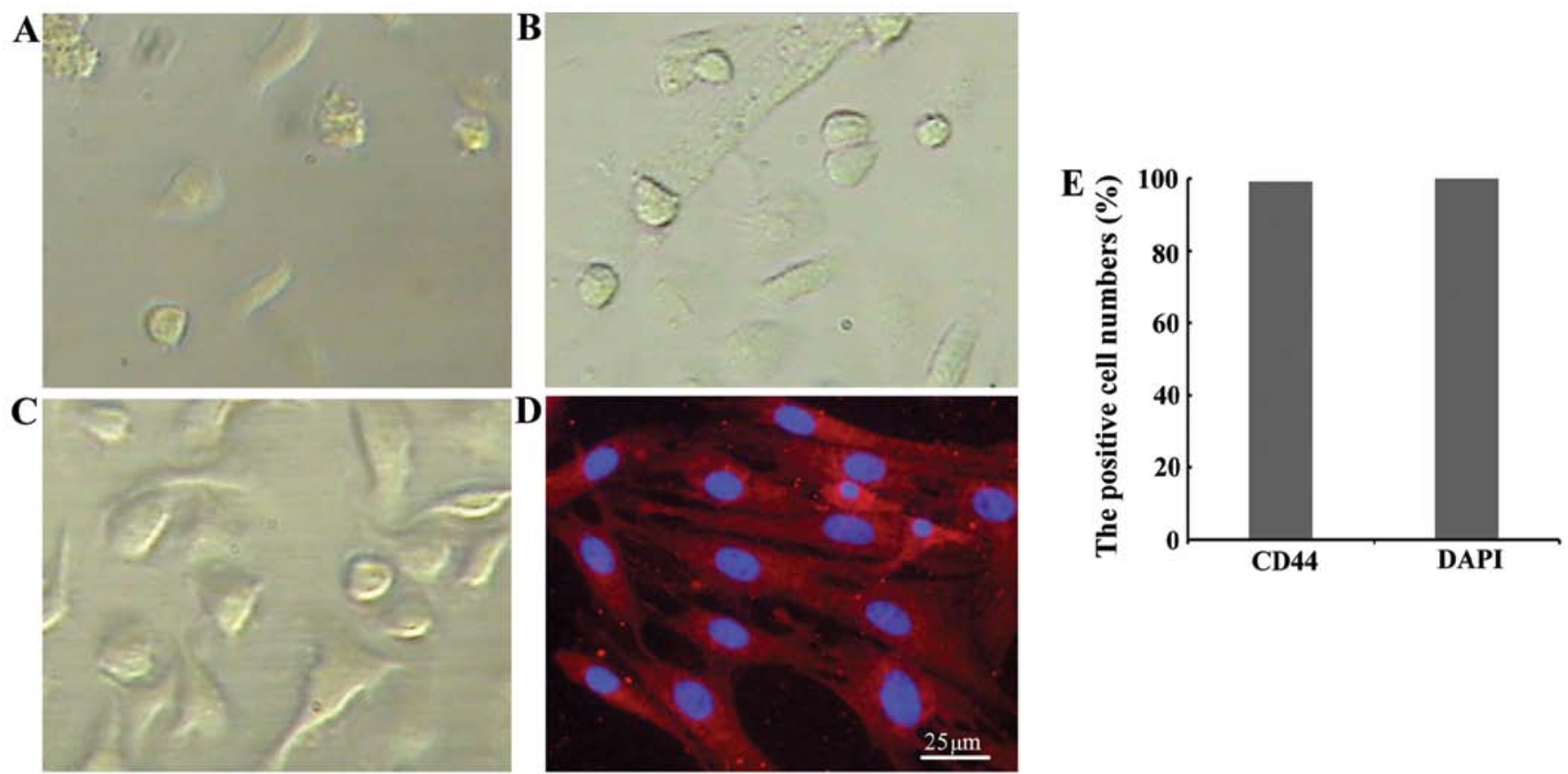

Figure 1. Appearance of the cultured bone marrow-derived mesenchymal stem cells (BMSCs). (A) BMSCs at 24 h post-culture; some adherent round cells could be seen. (B) BMSCs at $72 \mathrm{~h}$ post-culture; there were some round and oval cells. (C) The number of BMSCs increased at 5 days post-culture and the cells in a spindle primarily forms grew into fiber or polygonal shapes. (D) Immunofluorescence staining for CD44, approximately 99.3\% cells were CD44-positive cells (red immunofluorescence). Scar bar, $25 \mu \mathrm{m}$. (E) Bar chart of the percentages of CD44-positive cells.

A

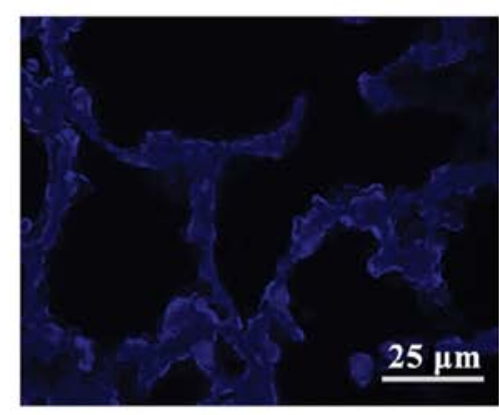

C

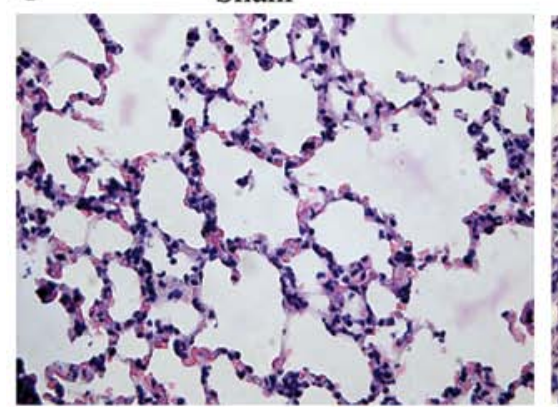

B

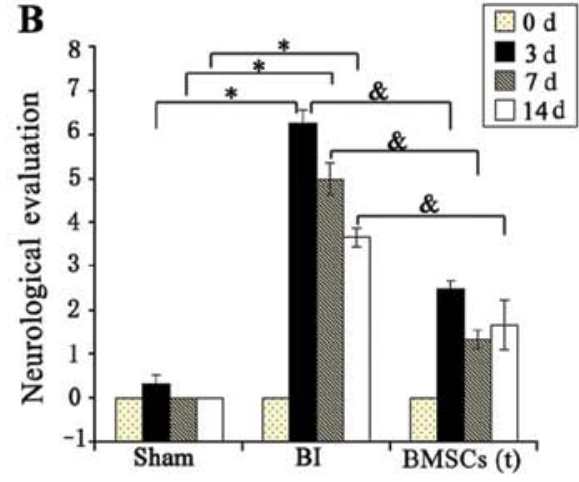

D

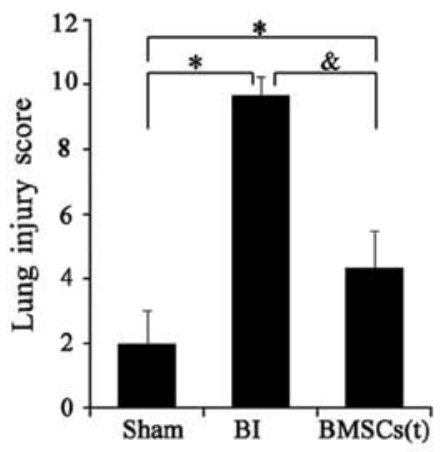

BMSCs ( $\mathrm{t})$
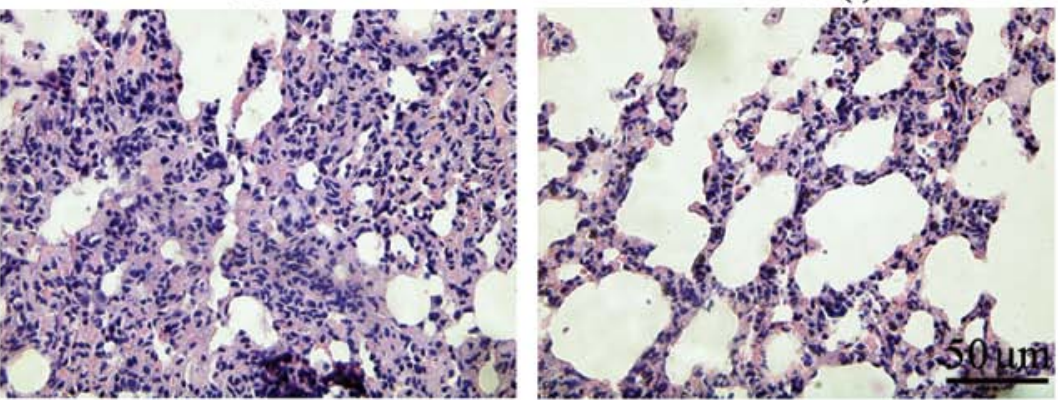

Figure 2. Bone marrow-derived mesenchymal stem cell (BMSC) transplantation improves behavioral and lung function. (A) BMSCs with Hoechst blue staining were widely diffused in the injured lung tissues at 14 days post-transplantation. Scar bar, $25 \mu \mathrm{m}$. (B) Neurological evaluation scores among the sham-operated (Sham), brain ischemia (BI) and BMSC groups at day 0-14 (d, days) post-transplantation. There was a statistically significant difference among the groups as determined by one-way ANOVA ("P<0.05 vs. Sham; ${ }^{\&} \mathrm{P}<0.05$ vs. BI group). Data are presented as the means $\pm \mathrm{SD}$ ( $\left.\mathrm{n}=8\right)$. (C) Representative photomicrographs of H\&E-stained lung sections in the Sham, BI and BMSCs transplantation [BMSCs (t)] groups at 14 days post-transplantation. Scar bar, $50 \mu$ m. (D) Lung injury scores among the Sham, BI and BMSCs (t) groups at 14 days post-transplantation. There was a statistically significant difference among the groups as determined by one-way ANOVA ( $\mathrm{P}<0.05$ vs. Sham; ${ }^{\&} \mathrm{P}<0.05$ vs. BI group). Data are presented as the means \pm SD $(\mathrm{n}=5)$.

and the neurological assessment scores in this group were significantly lower than those in the $\mathrm{BI}$ group ( $\mathrm{P}<0.05$; Fig. $2 \mathrm{~B})$.
In order to observe the effect of BMSC transplantation on lung tissues following permanent focal cerebral ischemia, we 


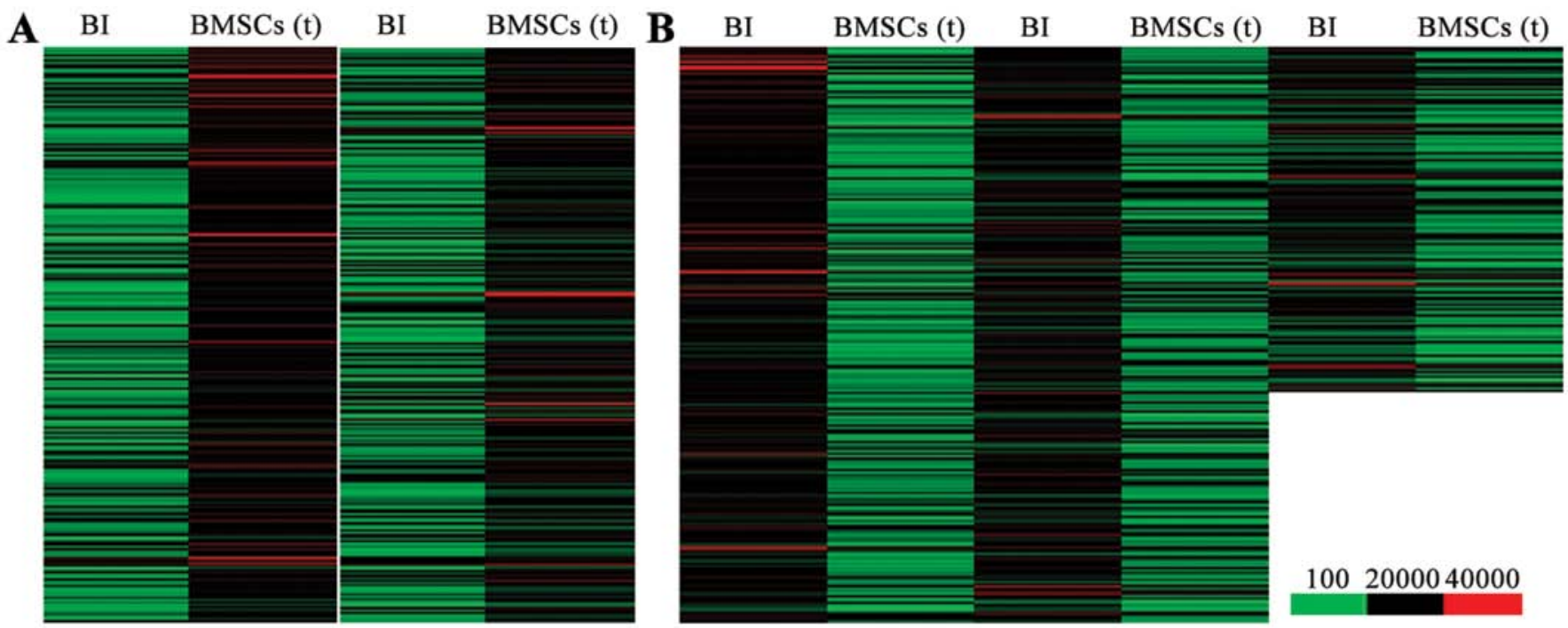

Figure 3. Expression of differentially expressed genes. (A) Heatmap of the upregulated differentially expressed genes in the bone marrow-derived mesenchymal stem cell (BMSC) transplantation [(BMSC) (t)] group vs. the brain ischemia (BI) group. (B) Heatmap of the downregulated differentially expressed genes in the BMSC (t) group vs. the BI group.

used the lung injury pathological scores to evaluate lung injury. $\mathrm{H} \& \mathrm{E}$ staining of the lung tissues revealed evident inflammatory cell infiltration and alveolar edema in the BI group, compared with the sham-operated group, whereas the BMSC group exhibited less inflammatory cell infiltration (Fig. 2C). In addition, the lung injury scores indicated that the scores of the BI group were higher than those of the sham-operated group $(\mathrm{P}<0.05)$, while the scores in BMSCs $(\mathrm{t})$ group were lower than that in the BI group $(\mathrm{P}<0.05)$ (Fig. 2D).

Differentially expressed genes between the BMSC transplantation and BI groups. In order to elucidate the molecular mechanisms responsiblef or the benefical effects of BMSC transplantation on cerebral ischemia-induced lung injury, we used Agilent Feature Extraction software to compare and analyze the differentially expressed genes between the BI group and BMSC transplantation group. Genes in signal intensity (normalized intensity) ratio $>2$ or 0.5 were defined as differentially expressed genes. We found that, compared with the lung tissues from the rats in the $\mathrm{BI}$ group, there were 1,836 upregulated genes (Fig. 3A) and 2,869 downregulated genes (Fig. 3B) in the lung tissues from the BMSC transplantation group.

Biological process analysis of the upregulated genes. In the 1,836 upregulated genes in the in the lung tissues from the BMSC transplantation group, we could see the cascade relationship of the biological pathways according to the P-value tree (Fig. 4A). According to the number of different genes measured, we selected the top 10 biological pathways for classification (Fig. 4B): 351 genes were involved in biological regulation, 329 genes were involved in the biological regulatory pathway, 314 genes were involved in the cell regulation pathway, 304 genes were involved in the stress pathway, 256 genes were involved in multi-cellular organisms pathways, 234 were involved in the cellular stress pathway, 215 were involved in cell communication pathways, 209 were involved in signaling pathways, 200 were involved in development pathways and 181 were involved in the developmental pathways of anatomical structure. According to the enrichment factor, we selected the top 10 biological pathways (Fig. 4C): lymphocyte chemotaxis, nephron tubule morphogenesis, positive regulation of kidney development, negative regulation of lipid catabolic process, negative regulation of appetite, dendritic cell differentiation, migration and cilium movement of lymphocytes, adenohypophysis development and renal tubule morphogenesis. According to the enrichment points, we selected the top 10 biological pathways (Fig. 4D): immune system process, lymphocyte chemotaxis, cell differentiation pathway, the external stress, cell death regulation pathways, cellular development process, cell death, cell chemotaxis, regulation of death and multicellular organisms pathways.

Biological process analysis of the downregulated genes. In the 2,869 downregulated genes in the lung tissues from the BMSC transplantation group, we could see the cascade relationship of the biological process according to the P-value tree (Fig. 5A). According to the number of different genes measured, we selected the top 10 biological process for classification (Fig. 5B): 1,583 gene processes, 1,002 were involved in cell metabolic processes, 830 participated in macromolecule metabolic processes, 733 were involved in cellular macromolecule metabolic processes, 670 were involved in developmental processes, 619 were involved in anatomical structure development, 607 were involved in the localization of biological processes and 595 participated in multicellular organism development. According to the enrichment factor, we selected the top 10 biological process (Fig. 5C): purine nucleotide metabolic process, regulation of DNA biosynthesis process, NADH metabolic process, heparin sulfate proteoglycan biosynthesis process, protein heterotrimerization, branching involved in salivary gland morphogenesis, retinal vasculature development camera-type eye, renal system vasculature development, kidney vasculature development and glomerulus vasculature 
A

B GO biological process classification

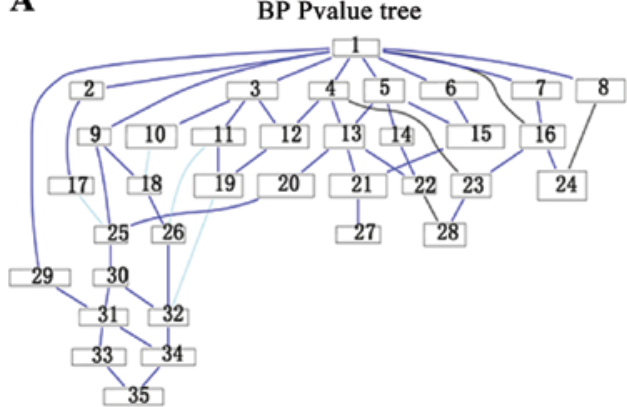
=biological regulation (351)

$\square$ regulation of biological process (329)
$\square$ regulation of cellular process (314)

aresponse to stimulus (304)

$\square$ multicellular organismal process (256)

w cellular response to stimulus(234)

$\square$ cell communication (215)

usignaling (209)

$\amalg$ developmental process $(200)$

$\square$ anatomical structure development $(181)$

C

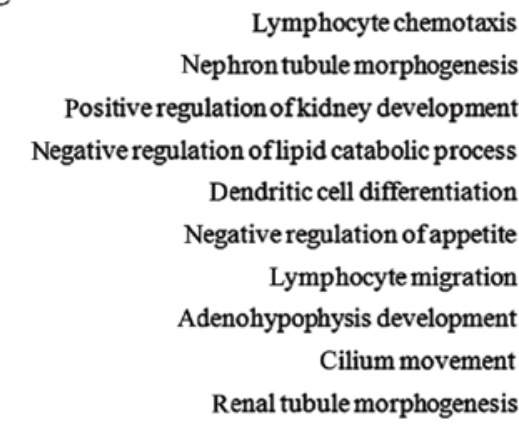

Sig GO terms DE gene-BP

D

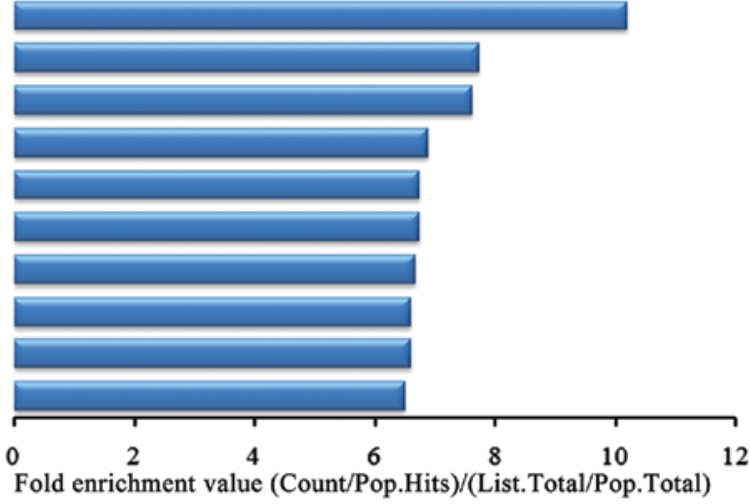

Sig GO terms DE gene-BP

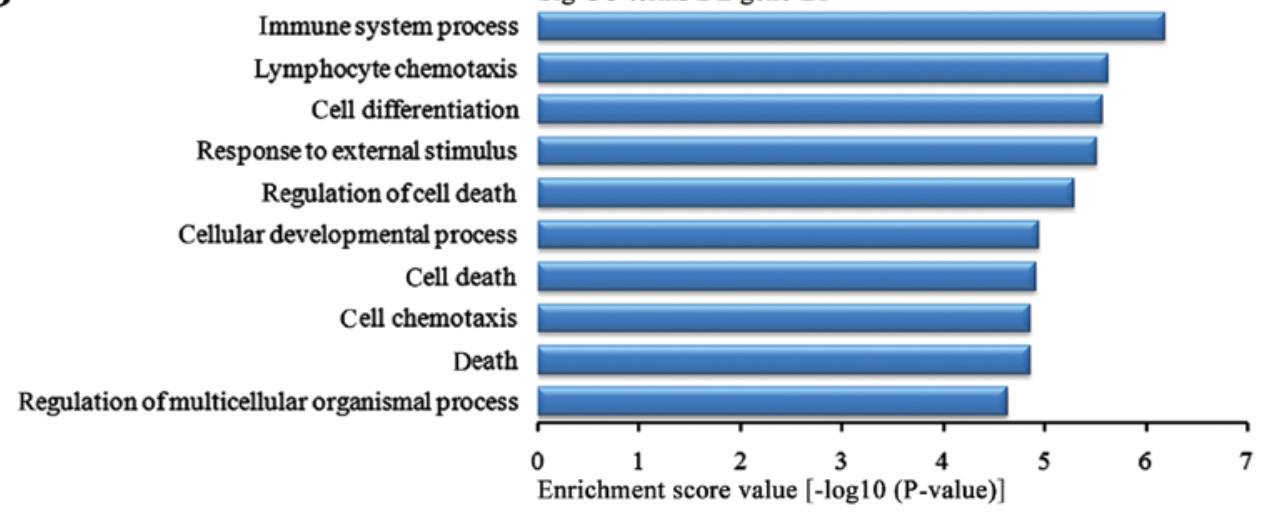

Figure 4. Analysis of the biological process for the upregulated genes in the bone marrow-derived mesenchymal stem cell (BMSC) transplantation [(BMSC) (t)] group vs. the brain ischemia (BI) group. (A) The biological process P-value tree. (B) Biological pathways classification according to the number of measured differentially expressed genes. (C) The map of the top 10 biological process according to enrichment factor. (D) The map of the top 10 biological process according to enrichment points. DE, differentially expressed.

development. According to the enrichment points, we selected the top 10 biological process (Fig. 5D): cardiovascular system development, circulatory system development, the blood vascular development, vasculature development, cell adhesion, biological adhesion, cell migration, localization, regulation of cell migration and development process.

Cell components analysis of the upregulated genes. In the 1,836 upregulated genes in the lung tissue from the BMSC transplantation group, we could see the cascade relationship of the cell components according to the P-value tree (Fig. 6A), and according to the number of different genes measured, the top 10 cell components were selected for classification (Fig. 6B): 533 genes were involved in cell part, 533 were involved in cell, 168 were involved in cell periphery, 163 were involved in plasma membrane, 82 were involved in cytoskeleton, 76 were involved in plasma membrane, 66 were involved in cell projection, 62 were involved in the cytoskeleton, 46 were involved in extracellular voids and 43 were involved in neuronal projection. According to the enrichment factor, we selected the top 10 cell components (Fig. 6C): axon initial segment, the immunological synapse, keratin fibers, platelet $\alpha$ granule potassium channel complex, dynein complex, aggresome, cilium axoneme, cytoplasmic stress granule, phagocytic vesicle, voltage-gated potassium channel complex. According to the enrichment points, we selected the top 10 cell components (Fig. 6D): keratin fibers, cell periphery, plasma membrane, the intermediate filaments, cell part, cell, synapse, extracellular space and synapse part.

Cell components analysis of the downregulated genes. In the 2,869 downregulated genes in the lung tissues from the BMSC transplantation group, we can see the cascade relationship of the cell components according to the P-value 
$\mathbf{A}$

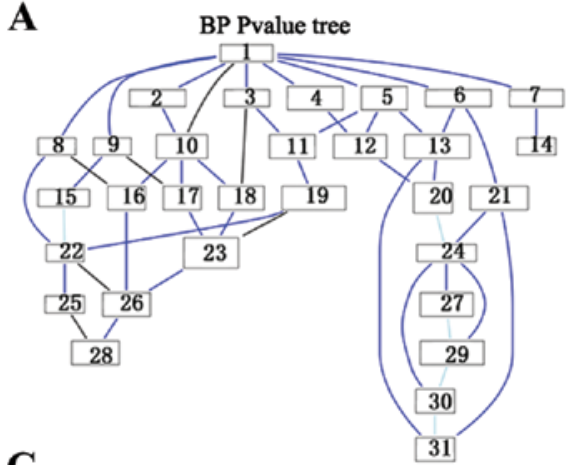

C

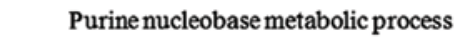

Regulation of DNA biosynthetic process Protein heterotrimerization Heparan sulfate proteoglycan biosynthetic process NADH metabolic process

Branching involved in salivary gland morphogenesis Retina vasculature development in camera-type eye Glomerulus vasculature development

Kidney vasculature development Renal system vasculature development

\section{8}

D
B GO biological process classification

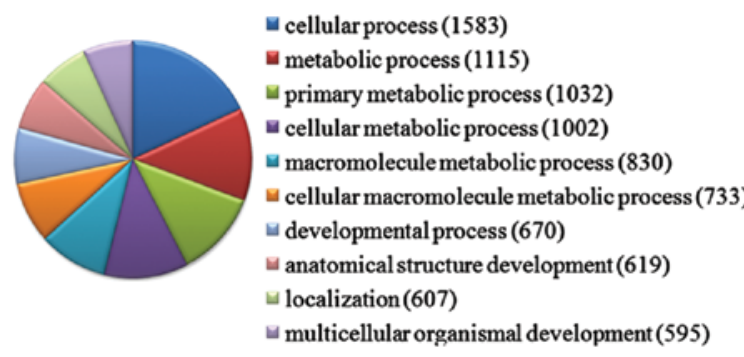

Sig GO terms DE gene-BP

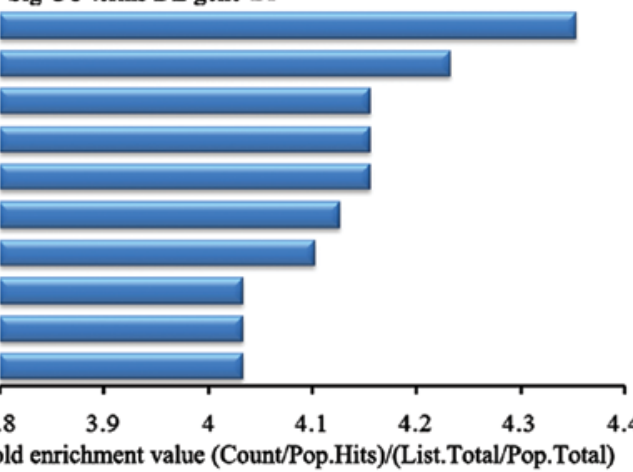

Sig GO terms DE gene-BP

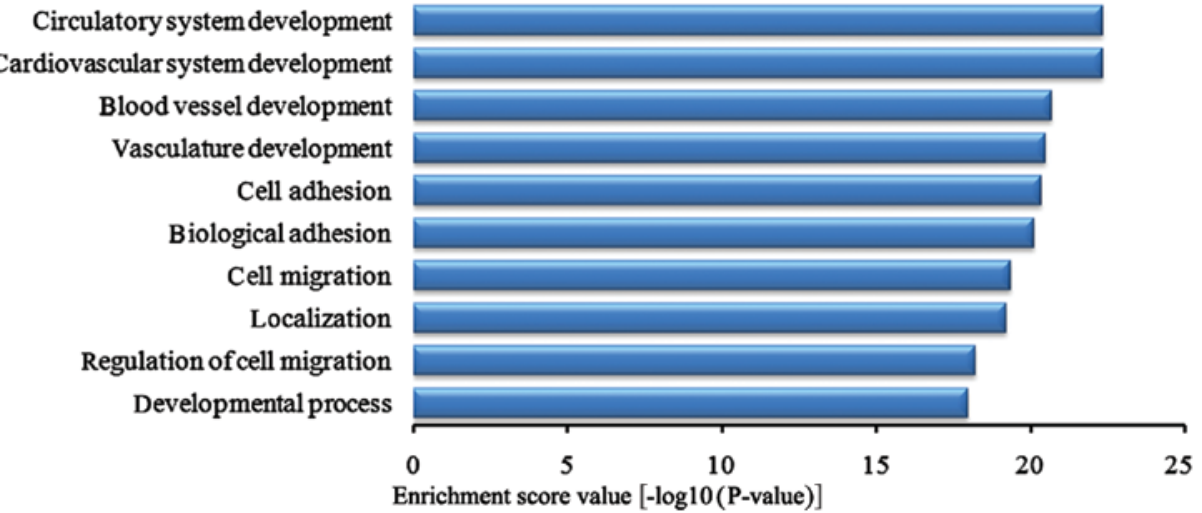

Figure 5. Analysis of the biological process for the downregulated genes in the bone marrow-derived mesenchymal stem cell (BMSC) transplantation [(BMSC) (t)] group vs. the brain ischemia (BI) group. (A) The biological process P-value tree. (B) Biological process classification according to the number of measured differentially expressed genes. (C) The map of the top 10 biological process according to enrichment factor. (D) The map of the top 10 biological process according to enrichment points. DE, differentially expressed.

tree (Fig. 7A). And according to the number of different genes measured selected the top 10 cell components for classification (Fig. 7B): 1,727 genes participated cell, 1,725 were involved in cell part, 1,591 participated intracellular, 1,530 were involved in intracellular part, 1,326 were participated in the organelle, 1,322 were involved in the intracellular organelle, 1,227 participated in the cytoplasm, 1,209 were involved in membrane-bounded organelle, 1,205 participated in the intracellular membrane-bounded organelle and 970 participated in the membrane. According to the enrichment factor we selected the top 10 cell components (Fig. 7C): microchorillus membrane, Schmidt-Lanterman incisures, compact myelin, lamellipodium membrane, rough endoplasmic reticulum membrane, costamere, endoplasmic reticulum lumen, RNA cleavage factor complex, cis-Golgi network, and desmosomes. According to the enrichment points we selected the top 10 cell components (Fig. 7D): intracellular part, intracellular, cytoplasm, cell, cell part, membrane-bounded organelles, intracellular membrane-bounded organelles cytoplasmic part, organelle and intracellular organelles.

Molecular function analysis of the upregulated genes. In the 1,836 upregulated genes in the lung tissue from the BMSC transplantation group, we could see the cascade relationship of the molecular functions according to the P-value tree (Fig. 8A). According to the number of different genes measured, we selected the top 10 molecular functions for classification (Fig. 8B): 409 genes were associated with binding, 224 were associated with protein binding, 77 were associated with purine ribonucleotide binding, 77 were associated with ribonucleotide binding, 64 were associated with adenyl ribonucleotide binding, 63 were associated with ATP binding, 56 were associated with transporter activity, 52 were associated with transmembrane transporter activity, 50 were associated 
$\mathbf{A}$

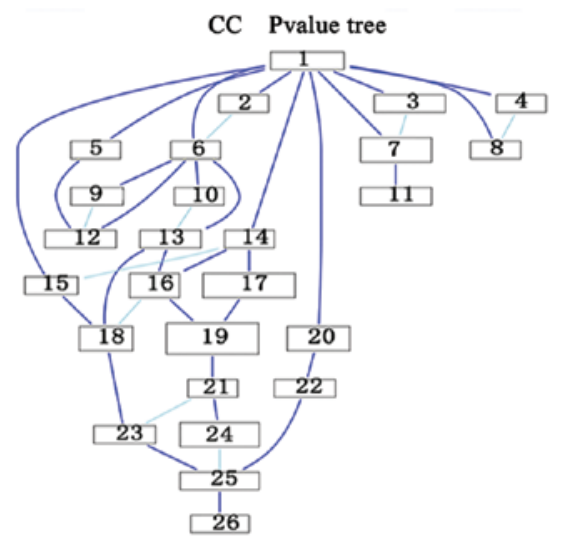

B GO biological process classification

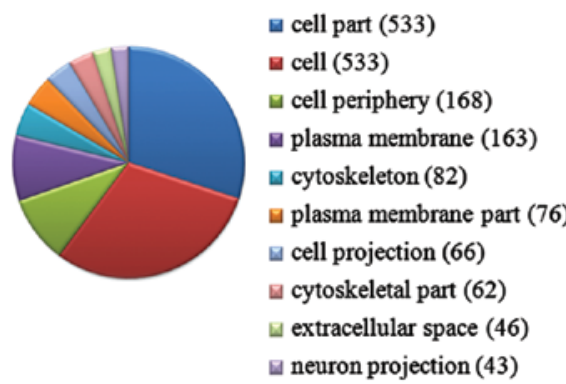

C

Sig GO terms DE gene-CC

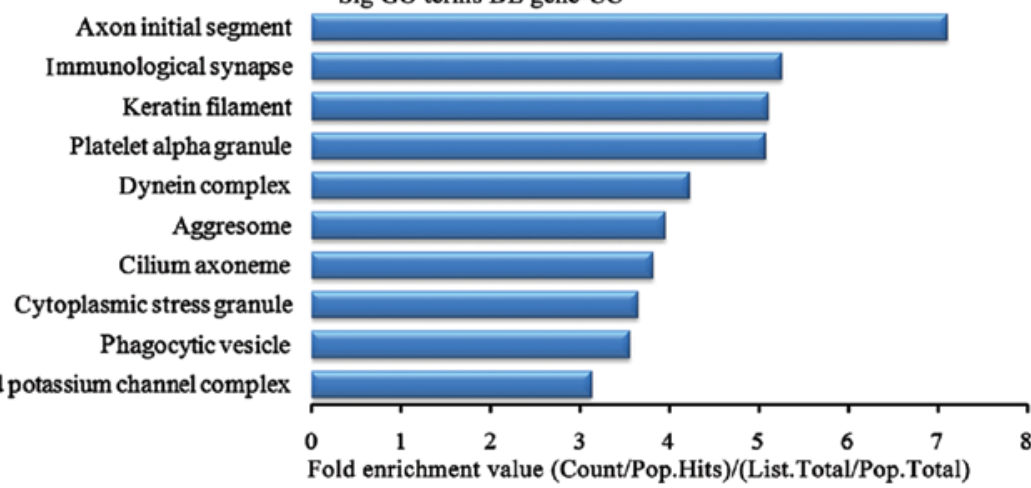

D

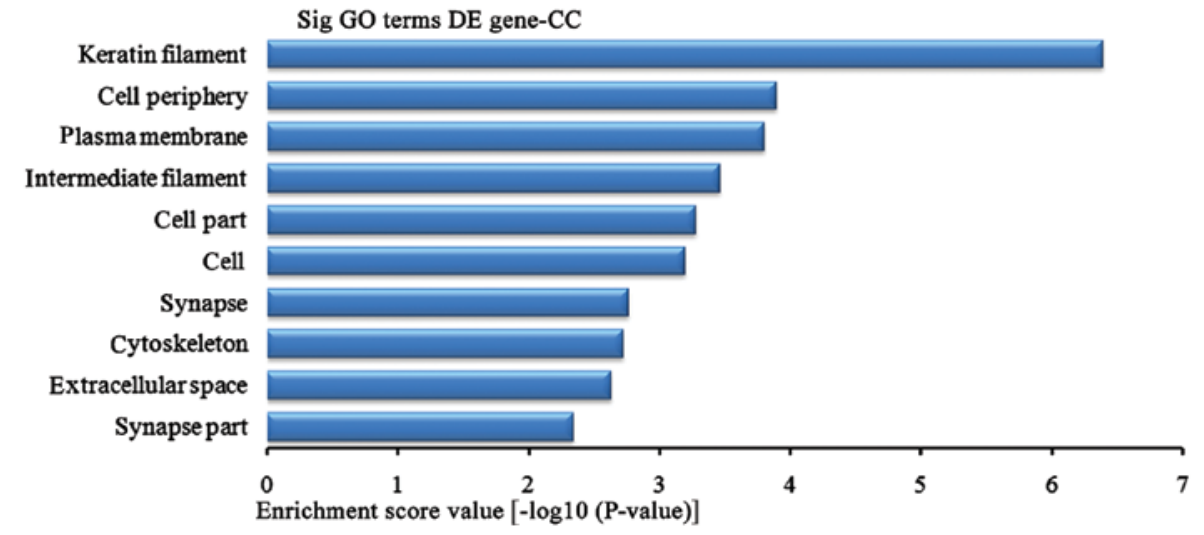

Figure 6. Analysis of the cell components for the upregulated genes in the bone marrow-derived mesenchymal stem cell (BMSC) transplantation [(BMSC) (t)] group vs. the brain ischemia (BI) group. (A) The cell components P-value tree. (B) Cell components classification according to the number of measured differentially expressed genes. (C) The map of the top 10 cell components according to enrichment factor. (D) The map of the top 10 cell components according to enrichment points. DE, differentially expressed.

with transfer activity. According to the enrichment factor, we selected the top 10 molecular functions (Fig. 8C): DNA $\mathrm{N}$-glycosylase activity, inorganic anion exchanger activity, MAP tyrosine/serine/threonine kinase activity, RNA polymerase II distal enhancer sequence-specific DNA binding, MAP kinase activity, syntaxin-1 binding, neurotransmitter transporter activity, translation elongation factor activity, neurotransmitter transporter activity and enhancer sequence-specific DNA binding. According to the enrichment points, we selected the top 10 molecular functions (Fig. 8D): metal ion transmembrane transporter activity, inorganic cation transmembrane transporter activity, cation transmembrane transporter activity, ion transmembrane transport activity, protein kinase activity, cation channel activity, DNA sequence-specific bind, protein binding, $\mathrm{G}$ protein-coupled receptors binding and chemokine activity.
Molecular function analysis of the downregulated genes. In the 2,869 downregulated genes in the lung tissue from the BMSC transplantation group, we could see the cascade relationship of the molecular functions according to the P-value tree (Fig. 9A). According to the number of different genes measured, we selected the top 10 molecular functions for classification (Fig. 9B): 1,392 genes were associated with binding, 795 were associated with protein binding, 771 were associated with catalytic activity, 425 were associated with ion binding, 422 were associated with cation binding, 414 were associated with metal ion binding, 382 were associated with small molecule binding, 355 were associated with nucleoside phosphate binding and 355 were associated with organic cyclic compound binding. According to the enrichment factor, we selected the top 10 molecular functions (Fig. 9C): transforming growth factor (TGF)- $\beta$ binding, 
$\mathbf{A}$

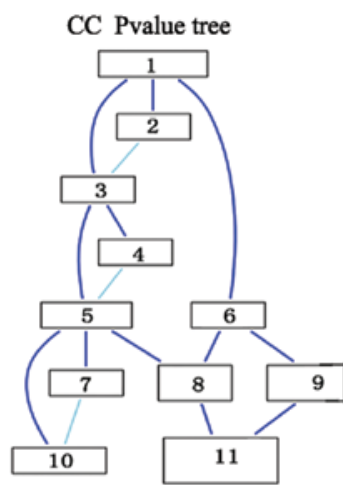

C

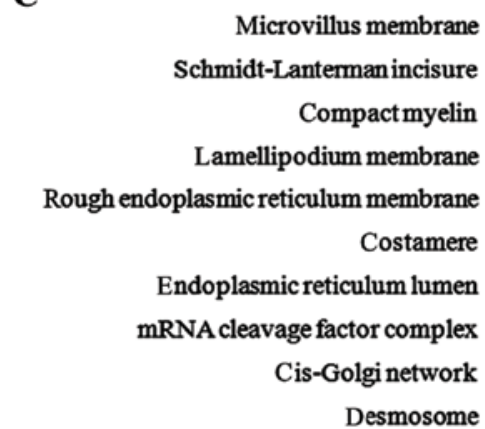

D

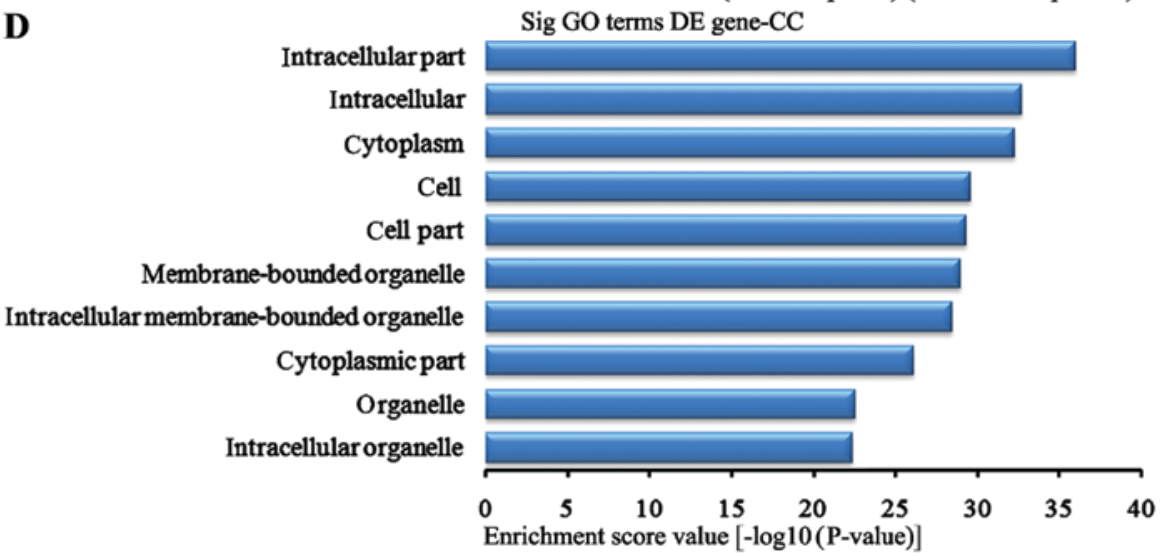

B $\quad$ GO biological process classification

a cell (1727)

- cell part (1725)

- intracellular(1591)

- intracellularpart (1530)

- organelle (1326)

intracellular organelle(1322)

$\because$ cytoplasm (1227)

membrane-bounded organellem(1209)

$\varpi$ intracellular membrane-bounded organelle(1205)

$\square$ membrane(970)

Sig GO terms DE gene-CC

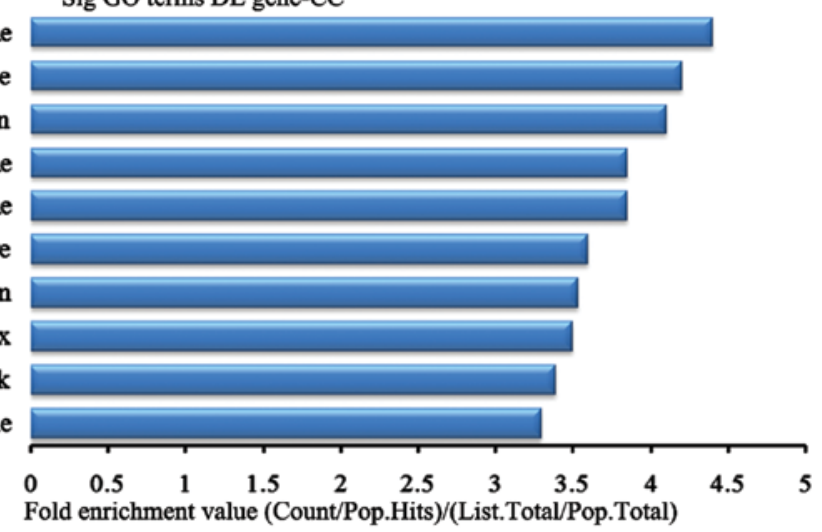

Sig GO terms DE gene-CC

Figure 7. Analysis of the cell components for the downregulated genes in the bone marrow-derived mesenchymal stem cell (BMSC) transplantation [(BMSC) (t)] group vs. the brain ischemia (BI) group. (A) The cell components P-value tree. (B) Cell components classification according to the number of measured differentially expressed genes. (C) The map of the top 10 cell components according to enrichment factor. (D) The map of the top 10 cell components according to enrichment points. DE, differentially expressed.

platelet-derived growth factor binding, vinculin binding, activin binding, transmembrane receptor protein serine/threonine kinase activity, TGF- $\beta$-activated receptor activity, fibronectin binding, extracellular matrix binding, laminin binding and low-density lipoprotein particle binding. According to the enrichment points, we selected the top 10 molecular functions (Fig. 9D): binding, protein binding, catalytic activity, ribonucleotide binding, purine nucleotide binding, small molecule binding, purine ribonucleoside triphosphate binding, nucleoside phosphate binding and nucleoside binding.

Related signaling pathway analysis of differentially expressed genes. To further study the function of the differentially expressed genes in the lung tissues between the BI group and the BMSC ( $\mathrm{t}$ ) group, we used the KEGG database for pathway analysis. The experimental results revealed that in this experiment, the striking upregulated different genes in the BMSC (t) group were mainly distributed in 40 signaling pathways when compared with the BI group (data not shown), while the striking downregulated different genes in the BMSC ( $t$ ) group were mainly distributed in 59 signaling pathways (data not shown). The upregulated differentially expressed genes were sorted in descending order according to the enrichment score. The top 10 signaling pathways (Fig. 10A) were as follows: the hematopoietic cell lineage, rheumatoid arthritis, circadian entrainment, cytokine-cytokine receptor interaction, MAPK signaling pathway, osteoclast differentiation, leishmaniasis, dopaminergic synapses, nuclear factor- $\mathrm{B}(\mathrm{NF}-\kappa \mathrm{B})$ signaling pathway and Staphylococcus infection. In addition, the top 10 signaling pathways for the downregulated different genes (Fig. 10B) 


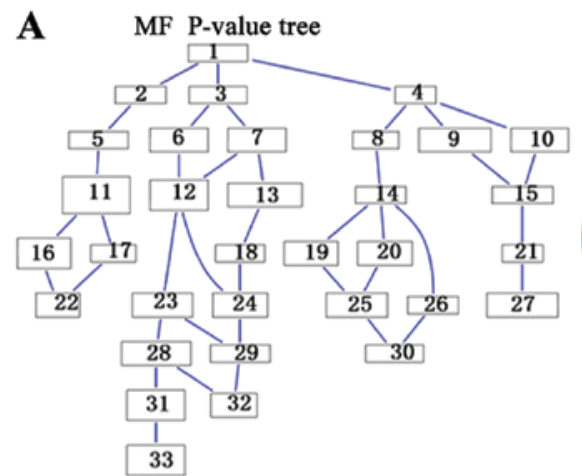

C

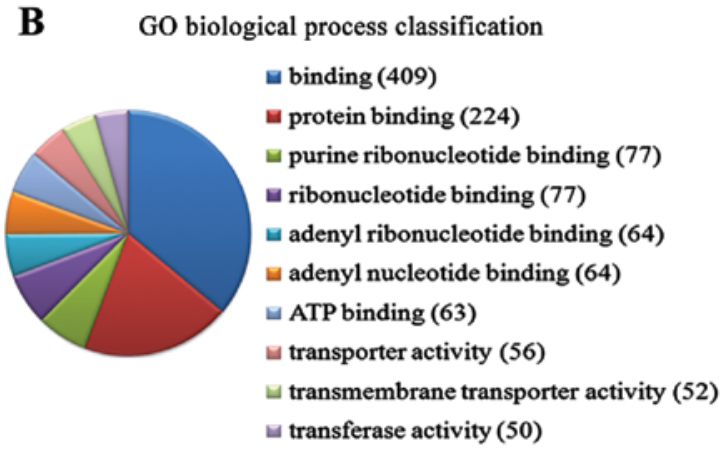

Sig GO terms DE gene-MF

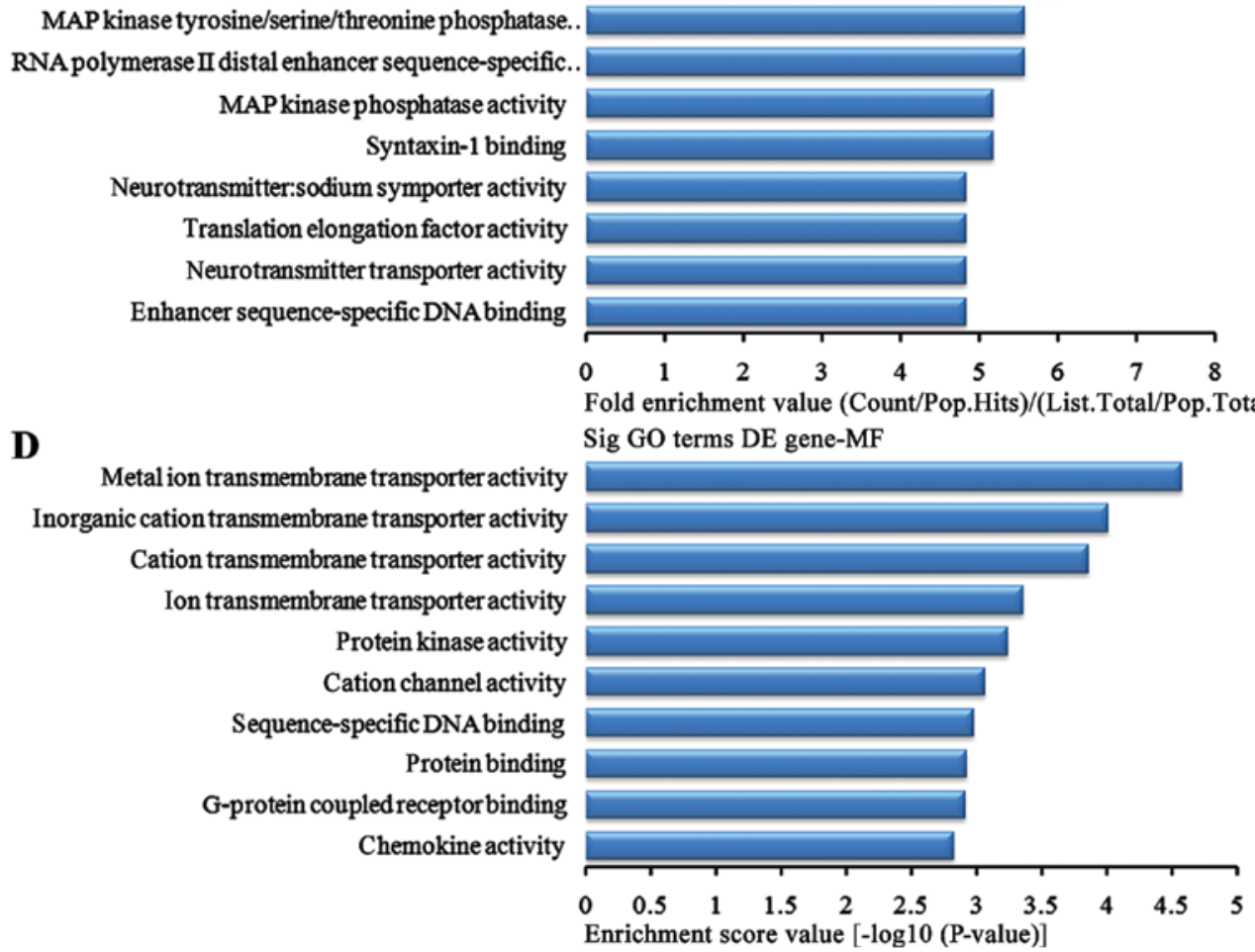

Figure 8. Analysis of the molecular functions for the upregulated genes in the bone marrow-derived mesenchymal stem cell (BMSC) transplantation [(BMSC) (t)] group vs. the brain ischemia (BI) group. (A) The molecular functions P-value tree. (B) Molecular functions classification according to the number of measured differentially expressed genes. (C) The map of the top 10 molecular functions according to enrichment factor. (D) The map of the top 10 molecular functions according to enrichment points. DE, differentially expressed.

were as follows according to the enrichment score: protein processing in the endoplasmic reticulum, focal adhesion, lysosome, the phosphoinositide 3-kinase (PI3K)-AKT signaling pathway, ECM-receptor interaction, proteoglycans in cancer, citrate cycle (TCA cycle), leukocyte transendothelial migration, hypoxia-inducible factor 1 (HIF-1) signaling pathway and bacterial invasion of epithelial cells.

\section{Discussion}

The main finding of this study is that BMSC transplantation via the rat tail vein to the lung tissues attenuates lung injury induced by permanent focal cerebral ischemia, associated with many differentially expressed genes. We established a model of permanent focal cerebral ischemia-induced lung injury model by MCAO, as indicated by the neurological evaluation and lung injury scores. BMSC transplantation improved neurological function and alleviated lung injury. In addition, microarray analyses revealed a total of 1,836 upregulated genes were and 2,869 downregulated genes. Biological process, cell component, molecular function and the signaling pathway of the differentially expressed genes were also analyzed and annotated. Notably, downregulated TGF- $\beta$, PDGF and the PI3K-AKT pathway were involved in the protective effects of BMSC transplantation.

Successful establishment of the model of permanent focal cerebral ischemia-induced lung injury. In this study, we established a model of permanent focal cerebral ischemia-induced lung injury model by MCAO. Neurological evaluation and histological analysis of the lung tissues were used to confirm the successful establishment of the model. As previously reported, in addition to local damage to the brain, permanent focal cerebral ischemia can lead to remote organ dysfunction (30-32), 
$\mathbf{A}$

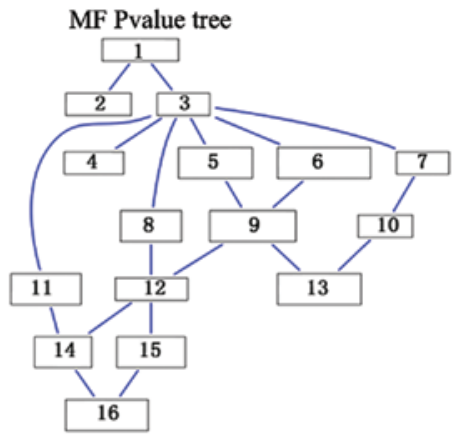

C

Transforming growth factor beta binding

Platelet-derived growth factor binding

Vinculin binding

Activin binding

Transmembrane receptor protein serine/threonine.

Transforming growth factor beta-activated receptor.

Fibronectin binding

Extracellularmatrix binding

Laminin binding

Low-density lipoprotein particle binding

D

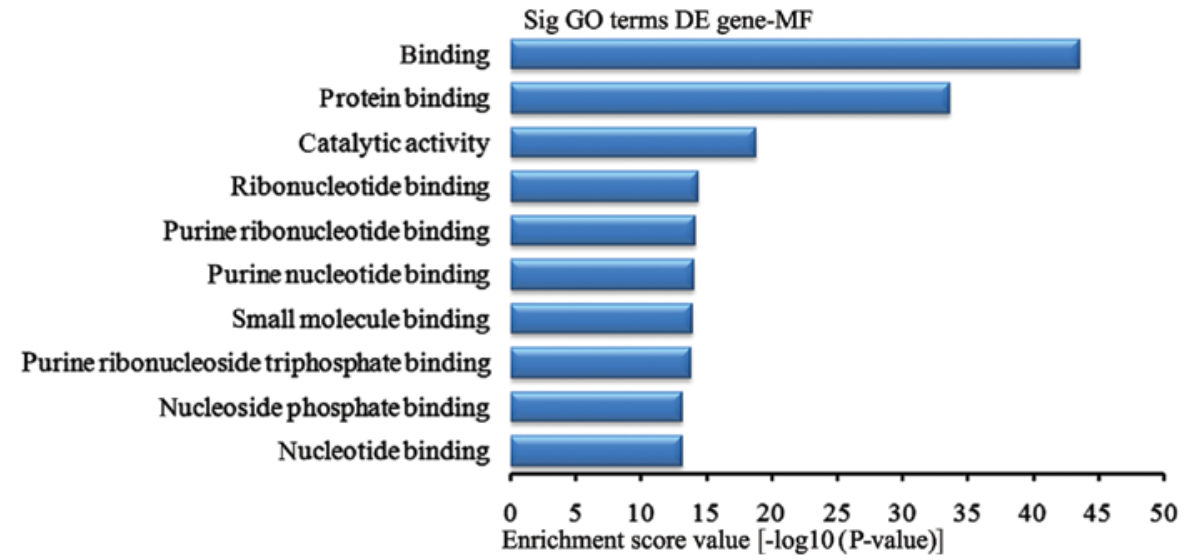

B GO biological process classification

abinding (1392)

aprotein binding (795)

$\square$ catalytic activity (771)

a ion binding (425)

acation binding (422)

$\square$ metal ion binding (414)

$\because$ small molecule binding (382)

$\square$ nucleotide binding (355)

$\triangle$ nucleoside phosphate binding (355)

⿶organic cyclic compound binding (355)

Sig GO terms DE gene- MF

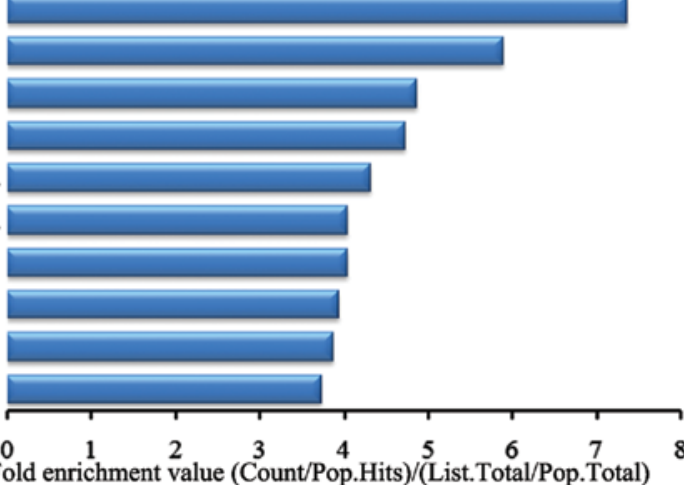

t/Pop Hits)/(List Tol/Pop Total) 
$\mathbf{A}$

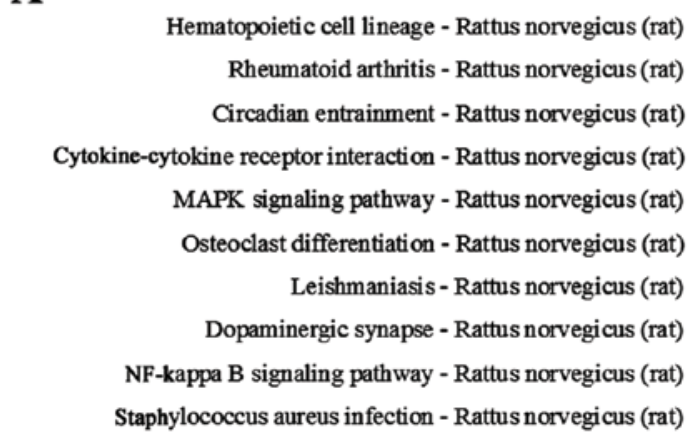

B

Protein processing in endoplasmic reticulum - Rattus norvegicus (rat)

Focal adhesion - Rattus norvegicus (rat)

Lysosome - Rattus norvegicus (rat)

PI3K-Akt signaling pathway - Rattus norvegicus (rat)

ECM-receptor interaction - Rattus norvegicus (rat)

Proteoglycans in cancer - Rattus norvegicus (rat)

Citrate cycle (TCA cycle) - Rattus norvegicus (rat)

Leukocyte transendothelial migration - Rattus norvegicus (rat)

HIF-1 signaling pathway - Rattus norvegicus (rat)

Bacterialinvasion of epithelial cells - Rattus norvegicus (rat)
Sig pathway of DE gene

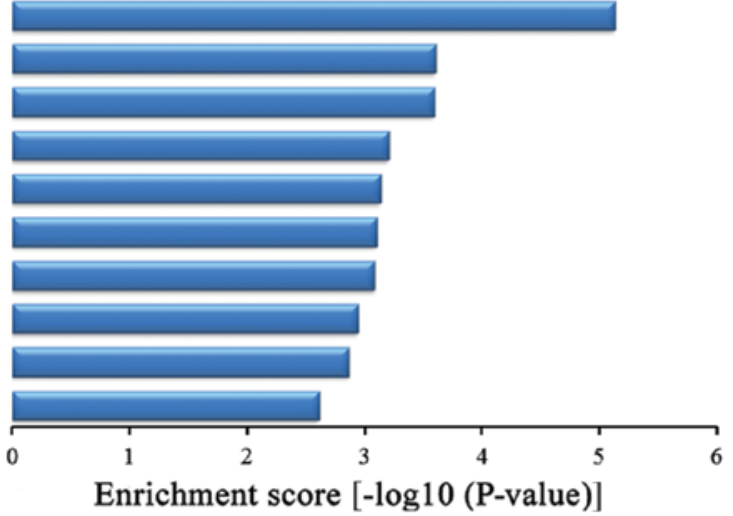

Sig pathway of DE gene

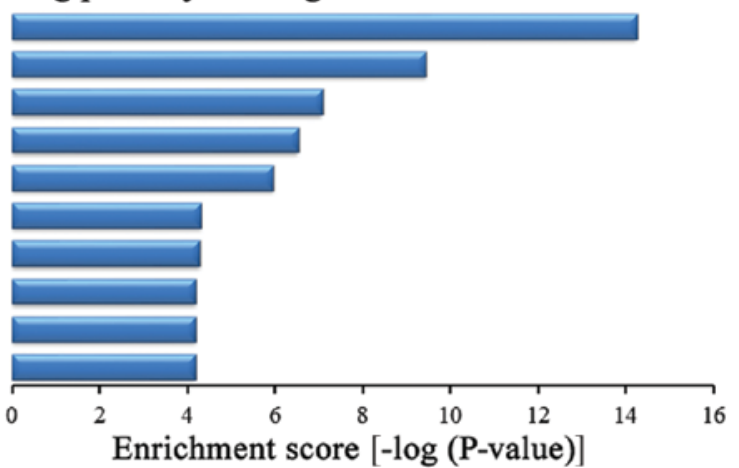

Figure 10. The signaling pathways of the differentially expressed genes. (A) The top 10 signaling pathways of the upregulated genes. (B) The top 10 signaling pathways of the downregulated genes. DE, differentially expressed.

medicine $(41,42)$ (expression profiling studies, gene mutation studies and gene component type and sequencing). Gene chip technology is able to analyze a high content of information, in a high-throughput manner, and is rapid and accurate (42). In addition, microarray and bioinformatics are complementary to Gene chip technology that were developed to be able to rapidly obtain large amounts of genetic information; they can provide the necessary database for bioinformatics research, while data analysis of gene chips also greatly depends on bioinformatics. Thus, the combination of both provides a fast channel to study molecular biology $(43,44)$.

Through gene microarray analysis, we found that, compared with the BI group, 1,836 genes were upregulated and 2,869 were downregulated in the lung tissues from the BMSCs $(\mathrm{t})$ group. This indicated that the effect of BMSC transplantation therapy in the lung tissue following cerebral ischemia was a multigene regulated complex process. In addition, the functions of the identified differentially expressed genes were involved in various biological processes, cellular component and molecular function and various related signal pathways.

Biological process analysis indicated that 1,836 upregulated genes in the BMSCs group were mainly involved in the processes of biological regulation, stress, development, immunological processes, lymphocyte chemotaxis, cell death regulation and ciliary movement. The 2,869 downregulated genes were mainly involved in metabolic processes, development process, DNA biosynthesis adjustment process, the cardiovascular system, cell adhesion, cell migration and positioning process. It has been shown that under acute stress conditions, mesenchymal stem cells and endothelial progenitor cells mobilize and provide a significant response, while HPA axia response and its key effect hormones-glucocorticoids exert an important regulatory effect (45-47). Additionally, researchers have found that the gene expression of early BMSCs played a supporting role in nerve repair in the development of the nervous system (48), and the endogenous ligand of rat-derived BMSCs could be antiapoptotic (49). Therefore, these studies combined with ours, indicated that the effects of BMSC transplantation for the treatment of cerebral ischemia and lung injury caused by cerebral ischemia were mediated by the interacting effects of multiple genes involved in the regulation of multiple systems.

In addition, molecular function analysis revealed that in the 2,869 downregulated genes, TGF- $\beta$ binding and PDGF binding played a role in the repair of lung injury. It has been shown that TGF- $\beta$ regulates the transformation of human lung fibroblasts into myofibroblasts through MAPK signal transduction pathways, producing extracellular matrix proteins and resulting in lung interstitial fibrosis (50). Lu et al confirmed that Smad2 plays a role in pulmonary vascular endothelial permeability induced by TGF- $\beta 1$; thus, increased TGF- $\beta 1$ may promote lung injury (51). Moreover, it has been shown that after experiencing hyoxia, the expression levels of PDGF-BB and PDGFR- $\beta$ were increased in the lung tissue, which suggested that PDGF participates in hyperoxia-induced lung injury (52). In addition, studies have found that PDGF stimulates mesenchymal cell hyperplasia and increases the deposition of extracellular matrix, which promotes the formation of pulmonary fibrosis $(53,54)$. In the model of lung fibrosis induced by radiation, radiation induces 
the high expression of PDGF, resulting in the phosphorylation of PDGF receptors, which activates downstream pathways; this process is inhibited by PDGF receptor tyrosine kinase inhibitor, attenuating the process of pulmonary fibrosis (55). In this study, we found that BMSC transplantation significantly reduced the TGF- $\beta$ and PDGF levels, which may alleviate lung injury caused by BI. Furthermore, related signaling pathway analysis indicated that in the BMSCs (t) group, the PI3K-AKT signaling pathway was downregulated, while the MAPK signaling pathway and $\mathrm{NF}-\kappa \mathrm{B}$ signaling pathway were upregulated. PI3K/AKT signaling pathway activation enhances the transcriptional activity of Smad3, the downstream protein of TGF- $\beta 1$, promoting the expression of type I collagen in fibroblasts, and thereby contributing to lung fibrosis (56). It has been demonstrated that in ALI, activated PAR2 in the alveolar epithelium increases the expression of $N F-\kappa B$ through the $\mathrm{PI} 3 \mathrm{~K} / \mathrm{PKB}$ signaling pathway, causing the release of inflammatory factors, such as PGE2 and COX-2, leading to alveolar epithelial injury; thus, the downregulation of the PI3K/PKB signal pathway can reduce alveolar injury (57).

We also found the pathway which promotes lung tissue survival: the hematopoietic cell lineage. Studies have indicated that tetraspin CD37 can directly mediate the signal transduction of survival and apoptosis (58), promoting dendritic cell migration (59), and contributing to cellular immunity and also promoting the long-term survival of plasma cells (60). Additionally, in this study, microarray analysis showed that BMSC transplantation can downregulate protein processing in the endoplasmic reticulum pathway, while ATF6 and $\mathrm{Bcl}-2$-associated athanohene (BAG2) were involved in this pathway. A previous study (61) demonstrated that ATF6 transcription differed between an endoplasmic reticulum stress (ERS) state and a no-ERS state. ATF6 upregulates the transcription and expression of XBP1 in the no-ERS state, while ATF6 reduces the transcription and expression of XBP1 in the ERS state. The BAG2 family can combine with the anti-apoptotic protein, Bcl-2, thus it is also known as the Bcl-2related anti-apoptotic protein family. It is mainly involved in the degration of intracellular proteins. Wang et al (62) reported that in thyroid cancer, the expression of BAG-2 promotes apoptosis in vitro and its apoptotic activity can be induced by proteasome inhibitor. Thus, the BMSC transplantation can improve behavioral and lung function following permanent focal cerebral ischemia, associated with the participation of multiple genes and signaling pathways.

In conclusion, the findings of the present study suggest that BMSC transplantation may repair lung injury following permanent focal cerebral ischemia. The present study may provide a new therapeutic strategy for BI-induced lung injury and may act as a guide for fundamental research and clinical research in the future.

\section{Acknowledgements}

We gratefully acknowledge the kind assistance and suggestions provided by Dr Qing-Jie Xia from West China Hospital, Sichuan University, China. This research was supported by a grant from the China National Science Foundation (nos. 81471268; 81271358 ) together with the program Innovative Research Team In Science and Technology in Yunnan Province.

\section{References}

1. Mozaffarian D, Benjamin EJ, Go AS, Arnett DK, Blaha MJ, Cushman M, de Ferranti S, Després JP, Fullerton HJ, Howard VJ, et al; American Heart Association Statistics Committee and Stroke Statistics Subcommittee: Heart disease and stroke statistics - 2015 update: A report from the American Heart Association. Circulation 131: e29-e322, 2015.

2. Cojocaru IM, Cojocaru M, Tănăsescu R, Iliescu I, Dumitrescu L and Silosi I: Expression of IL-6 activity in patients with acute ischemic stroke. Rom J Intern Med 47: 393-396, 2009.

3. Brüning CA, Prigol M, Luchese C, Jesse CR, Duarte MM, Roman SS and Nogueira CW: Protective effect of diphenyl diselenide on ischemia and reperfusion-induced cerebral injury: Involvement of oxidative stress and pro-inflammatory cytokines. Neurochem Res 37: 2249-2258, 2012.

4. Zeppellini R, Salsa F, Gheno G and Cucchini F: Cardiac injury in acute cerebral vasculopathy. Ann Ital Med Int 16: 73-81, 2001 (In Italian).

5. Alaro D, Bashir A, Musoke R and Wanaiana L: Prevalence and outcomes of acute kidney injury in term neonates with perinatal asphyxia. Afr Health Sci 14: 682-688, 2014.

6. Saeed F, Adil MM, Malik AA, Qureshi MH and Nahab F: Worse in-hospital outcomes in patients with transient ischemic attack in association with acute kidney injury: analysis of nationwide in-patient sample. Am J Nephrol 40: 258-262, 2014.

7. Sweetman DU, Riordan M and Molloy EJ: Management of renal dysfunction following term perinatal hypoxia-ischaemia. Acta Paediatr 102: 233-241, 2013.

8. Khatri M, Himmelfarb J, Adams D, Becker K, Longstreth WT and Tirschwell DL: Acute kidney injury is associated with increased hospital mortality after stroke. J Stroke Cerebrovasc Dis 23: 25-30, 2014.

9. Zhao S, Rong R, Dan QQ and Zhang YH: Expression of trkB gene in the pulmonary tissue of rats with lung injury induced by cerebral ischemia. Sichuan Da Xue Xue Bao Yi Xue Ban 43: 901-903, 2012 (In Chinese)

10. Wu YH, Zhang X and Wang DH: Role of asymmetric dimethylarginine in acute lung injury induced by cerebral ischemia/ reperfusion injury in rats. Nan Fang Yi Ke Da Xue Xue Bao 31: 1289-1294, 2011.

11. Liao F, Dan QQ, Du RF, Li JT, Zhang YH. Expression of TNF-alpha in lung tissue of rats with lung injury induced by brain ischemia. Sichuan Da Xue Xue Bao Yi Xue Ban 43: 914-917, 2012 (In. Chinese)

12. Lv Q, Wang SL, Jiang L, He X, Hu YD, Wang TH and Zhang YH: Identification of featured biomarkers between human lung adenocarcinoma and inflammatory pseudotumor using gene expression microarray. Idiscovery 2: 1-15, 2016.

13. Duan GX, Men XL and Peng J: The effects of tetramethylpyrazine on lung injury induced by brain ischemia/reperfusion. Zhongguo Ying Yong Sheng Li Xue Za Zhi 22: 361-362, 378 , 2006 (In Chinese).

14. Madala SK, Edukulla R, Schmidt S, Davidson C, Ikegami M and Hardie WD: Bone marrow-derived stromal cells are invasive and hyperproliferative and alter transforming growth factor$\alpha$-induced pulmonary fibrosis. Am J Respir Cell Mol Biol 50: 777-786, 2014.

15. Jansen BJ, Gilissen C, Roelofs H, Schaap-Oziemlak A, Veltman JA, Raymakers RAP, Jansen JH, Kögler G, Figdor CG, Torensma R, et al: Functional differences between mesenchymal stem cell populations are reflected by their transcriptome. Stem Cells Dev 19: 481-490, 2010.

16. Kitada $M$ and Dezawa $M$ : Induction system of neural and muscle lineage cells from bone marrow stromal cells; a new strategy for tissue reconstruction in degenerative diseases. Histol Histopathol 24: 631-642, 2009.

17. Vaquero J, Otero L, Bonilla C, Aguayo C, Rico MA, Rodriguez A and Zurita M: Cell therapy with bone marrow stromal cells after intracerebral hemorrhage: Impact of platelet-rich plasma scaffolds. Cytotherapy 15: 33-43, 2013.

18. Rippon HJ, Polak JM, Qin M and Bishop AE: Derivation of distal lung epithelial progenitors from murine embryonic stem cells using a novel three-step differentiation protocol. Stem Cells 24: 1389-1398, 2006

19. Serikov VB, Popov B, Mikhailov VM, Gupta N and Matthay MA: Evidence of temporary airway epithelial repopulation and rare clonal formation by BM-derived cells following naphthalene injury in mice. Anat Rec (Hoboken) 290: 1033-1045, 2007. 
20. Pati S, Gerber MH, Menge TD, Wataha KA, Zhao Y, Baumgartner JA, Zhao J, Letourneau PA, Huby MP, Baer LA, et al: Bone marrow derived mesenchymal stem cells inhibit inflammation and preserve vascular endothelial integrity in the lungs after hemorrhagic shock. PLoS One 6: e25171, 2011.

21. Uccelli A, Moretta L and Pistoia V: Mesenchymal stem cells in health and disease. Nat Rev Immunol 8: 726-736, 2008.

22. Shlyapnikov YM, Shlyapnikova EA and Morozov VN: Carboxymethyl cellulose film as a substrate for microarray fabrication. Anal Chem 86: 2082-2089, 2014.

23. Du JY, Yang H, Tian DR, Wang QM and He L: Identification and functional analysis of differentially expressed genes related to obesity using DNA microarray. Genet Mol Res 13: 64-72, 2014.

24. Ansari S, Azari H, McConnell DJ, Afzal A and Mocco J: Intraluminal middle cerebral artery occlusion (MCAO) model for ischemic stroke with laser doppler flowmetry guidance in mice. J Vis Exp 51: 2879, 2011.

25. He QQ, He X, Wang YP, Zou Y, Xia QJ, Xiong LL, Luo CZ, $\mathrm{Hu}$ XS, Liu J and Wang TH: Transplantation of bone marrowderived mesenchymal stem cells (BMSCs) improves brain ischemia-induced pulmonary injury in rats associated to TNF- $\alpha$ expression. Behav Brain Funct 12: 9, 2016.

26. Zhang Z, Yan Y, Sun B, Liu J and Zhu YH: Bone marrow stromal cells genetically modified by neurotrophin- 4 gene improve the cognitive ability in Alzheimer's disease model rats. Ibrain 2: 1-8, 2016.

27. Menzies SA, Hoff JT and Betz AL: Middle cerebral artery occlusion in rats: a neurological and pathological evaluation of a reproducible model. Neurosurgery 31: 100-106, 1992.

28. Liu MW, Su MX, Zhang W, Wang YQ, Chen M, Wang L and Qian CY: Protective effect of Xuebijing injection on paraquatinduced pulmonary injury via downregulating the expression of p38 MAPK in rats. BMC Complement Altern Med 14: 498, 2014

29. Luo H, Zhao X, Wan X, Huang S and Wu D: Gene microarray analysis of the IncRNA expression profile in human urothelial carcinoma of the bladder. Int J Clin Exp Med 7: 1244-1254, 2014

30. Sun L, Ai J, Wang N, Zhang R, Li J, Zhang T, Wu W, Hang P, Lu Y and Yang B: Cerebral ischemia elicits aberration in myocardium contractile function and intracellular calcium handling. Cell Physiol Biochem 26: 421-430, 2010.

31. Min J, Farooq MU, Greenberg E, Aloka F, Bhatt A, Kassab M, Morgan JP and Majid A: Cardiac dysfunction after left permanent cerebral focal ischemia: The brain and heart connection. Stroke 40: 2560-2563, 2009.

32. Watanabe WK: Brain-heart signaling after cerebral ischemia reperfusion injury. Int J Psychophysiol 69: 229-229, 2008.

33. Bratton SL and Davis RL: Acute lung injury in isolated traumatic brain injury. Neurosurgery 40: 707-712, 1997.

34. Sukhotnik I, Slijper N, Pollak Y, Chemodanov E, Shaoul R, Coran AG and Mogilner JG: Parenteral omega-3 fatty acids (Omegaven) modulate intestinal recovery after intestinal ischemiareperfusion in a rat model. J Pediatr Surg 46: 1353-1360, 2011.

35. Sayan H, Ozacmak VH, Sen F, Cabuk M, Atik DY, Igdem AA and Ozacmak ID: Pharmacological preconditioning with erythropoietin reduces ischemia-reperfusion injury in the small intestine of rats. Life Sci 84: 364-371, 2009.

36. Grommes $\mathbf{J}$ and Soehnlein O: Contribution of neutrophils to acute lung injury. Mol Med 17: 293-307, 2011.

37. Rojas M, Xu J, Woods CR, Mora AL, Spears W, Roman J and Brigham KL: Bone marrow-derived mesenchymal stem cells in repair of the injured lung. Am J Respir Cell Mol Biol 33: 145-152, 2005.

38. Kotton DN, Ma BY, Cardoso WV, Sanderson EA, Summer RS, Williams MC and Fine A: Bone marrow-derived cells as progenitors of lung alveolar epithelium. Development 128: 5181-5188, 2001

39. OrtizLA,Gambelli F,McBride C,GauppD,Baddoo M,KaminskiN and Phinney DG: Mesenchymal stem cell engraftment in lung is enhanced in response to bleomycin exposure and ameliorates its fibrotic effects. Proc Natl Acad Sci USA 100: 8407-8411, 2003.

40. Srinivasan A, Leung KP, Lopez-Ribot JL and Ramasubramanian AK: High-throughput nano-biofilm microarray for antifungal drug discovery. MBio 4: 4, 2013.

41. Jiang XS, Ni YQ, Liu TJ, Zhang M, Jiang R and Xu GZ: Generation and characterization of immortalized rat retinal microglial cell lines. J Neurosci Res 92: 424-431, 2014.

42. Yoshida M, Watanabe Y, Yamanishi K, Yamashita A Yamamoto H, Okuzaki D, Shimada K, Nojima H, Yasunaga T, Okamura $\mathrm{H}$, et al: Analysis of genes causing hypertension and stroke in spontaneously hypertensive rats: Gene expression profiles in the brain. Int J Mol Med 33: 887-896, 2014
43. Fu LJ and Wang B: Investigation of the hub genes and related mechanism in ovarian cancer via bioinformatics analysis. J Ovarian Res 6: 92, 2013

44. Ng CF, Xu JY, Li MS and Tsui SK: Identification of FHL2-regulated genes in liver by microarray and bioinformatics analysis. J Cell Biochem 115: 744-753, 2014.

45. Kinlein SA, Wilson CD and Karatsoreos IN: Dysregulated hypothalamic-pituitary-adrenal axis function contributes to altered endocrine and neurobehavioral responses to acute stress. Front Psychiatry 6: 31, 2015.

46. Zhu XY, Urbieta-Caceres V, Krier JD, Textor SC, Lerman A and Lerman LO: Mesenchymal stem cells and endothelial progenitor cells decrease renal injury in experimental swine renal artery stenosis through different mechanisms. Stem Cells 31: 117-125, 2013.

47. Brandl A, Meyer M, Bechmann V, Nerlich M and Angele P: Oxidative stress induces senescence in human mesenchymal stem cells. Exp Cell Res 317: 1541-1547, 2011

48. Nandoe Tewarie RD, Bossers K, Ritfeld GJ, Blits B, Grotenhuis JA, Verhaagen J and Oudega M: Early passage bone marrow stromal cells express genes involved in nervous system development supporting their relevance for neural repair. Restor Neurol Neurosci 29: 187-201, 2011

49. Zeng X, Yu SP, Taylor T, Ogle M and Wei L: Protective effect of apelin on cultured rat bone marrow mesenchymal stem cells against apoptosis. Stem Cell Res 8: 357-367, 2012.

50. Furukawa F, Matsuzaki K, Mori S, Tahashi Y, Yoshida K, Sugano Y, Yamagata H, Matsushita M, Seki T, Inagaki Y, et al: p38 MAPK mediates fibrogenic signal through Smad3 phosphorylation in rat myofibroblasts. Hepatology 38: 879-889, 2003.

51. Lu Q, Harrington EO, Jackson H, Morin N, Shannon C and Rounds S: Transforming growth factor-betal-induced endothelial barrier dysfunction involves Smad2-dependent p38 activation and subsequent RhoA activation. J Appl Physiol (1985) 101: 375-384, 2006.

52. Buch S, Han RN, Cabacungan J, Wang J, Yuan S, Belcastro R, Deimling J, Jankov R, Luo X, Lye SJ, et al: Changes in expression of platelet-derived growth factor and its receptors in the lungs of newborn rats exposed to air or $60 \% \mathrm{O}(2)$. Pediatr Res 48: 423-433, 2000

53. Lin Q, Fang LP, Zhou WW and Liu XM: Rosiglitazone inhibits migration, proliferation, and phenotypic differentiation in cultured human lung fibroblasts. Exp Lung Res 36: 120-128, 2010.

54. Kogan EA, Tyong FV and Demura SA: The mechanism of lung tissue remodeling in the progression of idiopathic pulmonary fibrosis. Arkh Patol 72: 30-36, 2010 (In Russian).

55. Abdollahi A, Li M, Ping G, Plathow C, Domhan S, Kiessling F, Lee LB, McMahon G, Gröne HJ, Lipson KE, et al: Inhibition of platelet-derived growth factor signaling attenuates pulmonary fibrosis. J Exp Med 201: 925-935, 2005.

56. Runyan CE, Schnaper HW and Poncelet AC: The phosphatidylinositol 3-kinase/Akt pathway enhances Smad3-stimulated mesangial cell collagen I expression in response to transforming growth factor-beta1. J Biol Chem 279: 2632-2639, 2004

57. Moriyuki K, Sekiguchi F, Matsubara K, Nishikawa H and Kawabata A: Proteinase-activated receptor-2-triggered prostaglandin $\mathrm{E}(2)$ release, but not cyclooxygenase-2 upregulation, requires activation of the phosphatidylinositol 3-kinase/Akt/ nuclear factor-kappaB pathway in human alveolar epithelial cells. J Pharmacol Sci 111: 269-275, 2009.

58. Lapalombella R, Yeh YY, Wang L, Ramanunni A, Rafiq S, Jha S, Staubli J, Lucas DM, Mani R, Herman SE, et al: Tetraspanin CD37 directly mediates transduction of survival and apoptotic signals. Cancer Cell 21: 694-708, 2012.

59. Gartlan KH, Wee JL, Demaria MC, Nastovska R, Chang TM, Jones EL, Apostolopoulos V, Pietersz GA, Hickey MJ, van Spriel $\mathrm{AB}$ and Wright MD: Tetraspanin CD37 contributes to the initiation of cellular immunity by promoting dendritic cell migration. Eur J Immunol 43: 1208-1219, 2013.

60. van Spriel AB, de Keijzer S, van der Schaaf A, Gartlan KH, Sofi M, Light A, Linssen PC, Boezeman JB, Zuidscherwoude M, Reinieren-Beeren I, et al: The tetraspanin CD37 orchestrates the $\alpha(4) \beta(1)$ integrin-Akt signaling axis and supports long-lived plasma cell survival. Sci Signal 5: ra82, 2012.

61. Guo FJ, Xiong Z, Lu X, Ye M, Han X and Jiang R: ATF6 upregulates XBP1S and inhibits ER stress-mediated apoptosis in osteoarthritis cartilage. Cell Signal 26: 332-342, 2014.

62. Wang HQ, Zhang HY, Hao FJ, Meng X, Guan Y and Du ZX: Induction of BAG2 protein during proteasome inhibitor-induced apoptosis in thyroid carcinoma cells. Br J Pharmacol 155: 655-660, 2008 